\title{
STUDIES ON THE SLOW DEPRESSIVE POTENTIAL OF THE ISOLATED FROG RETINA
}

\author{
Isao Hanawa, Kiyoshi Kuge And Katsuhiko Matsumura \\ Department of Physiology, Osaka City University Medical School, \\ Abeno-ku, Osaka, Japan
}

In a preceding paper (HANAwA, KUgE and MATSUMURA, 1967) it was reported that the slow transretinal dc potential change which resembles LEÃO's spreading cortical depression was evoked spontaneously when the receptor side of the retina was exposed to a solution containing high potassium ion concentration, azide or ouabain. The conclusion drawn from these observations that the structures being evoked this slow response lay closer to the receptor surface of the retina, and it was proposed that it was the response of the scleral portion of the Müller cells. Since the b-wave of the ERG is abolished by this slow potential change as the present work demonstrates, this slow response will be called the slow depressive potential (SDP). Gouras (1958) has shown that a similar dc shift associated with color change could occur in the isolated amphibian retina spontaneously at a point on the cut peripheral edge of the retina, and that it spread concentrically at a rate of $1 \pm 0.5 \mathrm{~mm} / \mathrm{min}$.

To investigate the physiological characteristics of the SDP, the application of the chemical agents such as azide, ouabain or high potassium ion solution was not appropriate, because the b-wave of the ERG disappeared completely when the SDP was evoked and never reappeared in a solution containing one of these agents. To overcome the difficulty, the following two kinds of solutions were devised to investigate the SDP. One was a solution containing $15 \mathrm{mM} \mathrm{Cl}$ ion that was placed on the receptor side, and the other was a $\mathrm{Cl}$-free solution that was placed on the vitreous side of the retina. By applying these solutions, the SDP could be evoked easily and regularly following a light stimulation at about $30 \mathrm{~min}$ intervals for a period of several hours, if the retina was kept in the dark.

In spite of a considerable amount of reports on the spreading cortical depression, we have less knowledge concerning the SDP in the retina. The experiments to be reported here aimed at investigating some properties of the SDP; such as the shape of potential change, effects of light and electrical stimulation, transretinal impedance change during the SDP, and depressive

Received for publication September 25, 1966.

㙵 功, 久家 洁, 松村克彦 
effect on the ERG; and to find the differences between the SDP and spreading cortical depression.

\section{METHOD}

Preparation and experimental solution. The isolated retina deprived of the pigment epithelium was dissected from the excised eye of bullfrogs (Rana catesbiana) and it was sandwitched between two thin acryl resin plates, each of which had a hole of $2 \mathrm{~mm}$ diameter in the middle, as described previously (see HANAwa, KUGE and MATSUMURA, 1967 for details). After a stable control amplitude of ERG was established in the initial control solution, the solutions on both sides of the retina were replaced by following solutions. One was a solution containing $15 \mathrm{mM} \mathrm{Cl}$ that was placed on the receptor side, and the other was a $\mathrm{Cl}$-free solution that was placed on the vitreous. side. Both solutions were prepared by adding sucrose after sodium chloride was replaced with sodium sulfate. The bathing solution was stirred throughout the experiment by a stream of pure oxygen bubbles saturated with vapor.

The solutions used for this experiment had the following composition (mM).

Initial control solution: $\mathrm{NaCl}, 72.0 ; \mathrm{KCl}, 2.5 ; \mathrm{MgSO}_{4}, 1.2 ; \mathrm{Na}_{2} \mathrm{SO}_{4}, 0.6 ; \mathrm{NaHCO}_{3}, 25.0$; $\mathrm{NaH}_{2} \mathrm{PO}_{4}, 3.0$; calcium gluconate, 0.9 ; glucose, 26. 0 .

$15 \mathrm{mM} \mathrm{Cl}$ solution: $\mathrm{NaCl}, 15.0 ; \mathrm{K}_{2} \mathrm{SO}_{4}, 1.25 ; \mathrm{MgSO}_{4}, 1.2 ; \mathrm{Na}_{2} \mathrm{SO}_{4}, 29.1 ; \mathrm{NaHCO}_{3}, 25.0$; $\mathrm{NaH}_{2} \mathrm{PO}_{4}, 3.0$; calcium gluconate, 0.9 ; glucose, 26. 0 ; sucrose, 29.75.

Cl-free solution: $\mathrm{Na}_{2} \mathrm{SO}_{4}, 36.6 ; \mathrm{K}_{2} \mathrm{SO}_{4}, 1.25 ; \mathrm{MgSO}_{4}, 1.2 ; \mathrm{NaHCO}_{3}, 25.0 ; \mathrm{NaH}_{2} \mathrm{PO}_{4}, 3.0$; calcium gluconate, 0.9 ; glucose, 26.0 ; sucrose, 37.25 .

Recording system. The transretinal potential was monitored by two narrow agar bridges, that were made by 4 per cent agar and the initial control solution, connected through calomel half-cells to a push-pull pre-amplifier DC-coupled. The SDP was recorded on a chopper type direct writing DC amplifier. In order to determine the size of the ERG during the SDP, the signal from the output end of the pre-amplifier was fed into an oscilloscope through a RC-coupled amplifier with a time constant of $1 \mathrm{sec}$. The retinal responses were measured at room temperature $\left(15-20^{\circ} \mathrm{C}\right.$.).

Impedance measurement. The transretinal impedance change during the SDP was measured with an alternating current bridge operated at a fixed frequency of $1000 \mathrm{cps}$. The potential of the measuring current obtained from an audio-oscillator was attenuated to about $100 \mathrm{mV}$ which is below threshold for the evolution of the SDP. The output potential of the A.C. Wheatston bridge was amplified and made visible on an oscilloscope screen. Simultaneously, the resistance changes were recorded by feeding the amplified and rectified output of the bridge into a chopper type direct writing DC amplifier. The resistance electrodes were platinum discs of $2 \mathrm{~cm}$ diameter, plated with platinum black and placed into each compartment.

Stimulation. Light stimulation was provided by a xenon flash lamp, which was reduced to an appropriate intensity by neutral filters inserted in the pathway of light.

For electric stimulation of the retina, electronically controlled rectangular potential changes, $1 \mathrm{msec}$ in duration, were applied through a pair of $\mathrm{Ag} \cdot \mathrm{AgCl}$ electrodes. To avoid poisoning by metal ions, the stimulating electrodes were placed in another chambers, each of which was connected to bathing solutions by a $\mathrm{NaCl}$-agar bridge. 


\section{RESULTS}

1. Shape and size of the SDP. When a solution containing $15 \mathrm{mM} \mathrm{Cl}$ and a $\mathrm{Cl}$-free solution were placed on the receptor and the vitreous side respectively, the transretinal dc potential differences for twenty retinas was $+0.30 \pm 0.05$ $\mathrm{mV}$. All potential differences were measured as the potential on the receptor side with respect to the vitreous side and the mean value is shown with standard deviation. In this circumstance the SDP could be evoked easily by a single flash. The elicitation of the SDP was also sometimes observed when the bathing solution was replaced by a fresh low chloride solution. Presumably this is due to a mechanical stimulation exerted on the retina. FIG. 1A shows a typical record of the SDP which appeared after light stimulation had

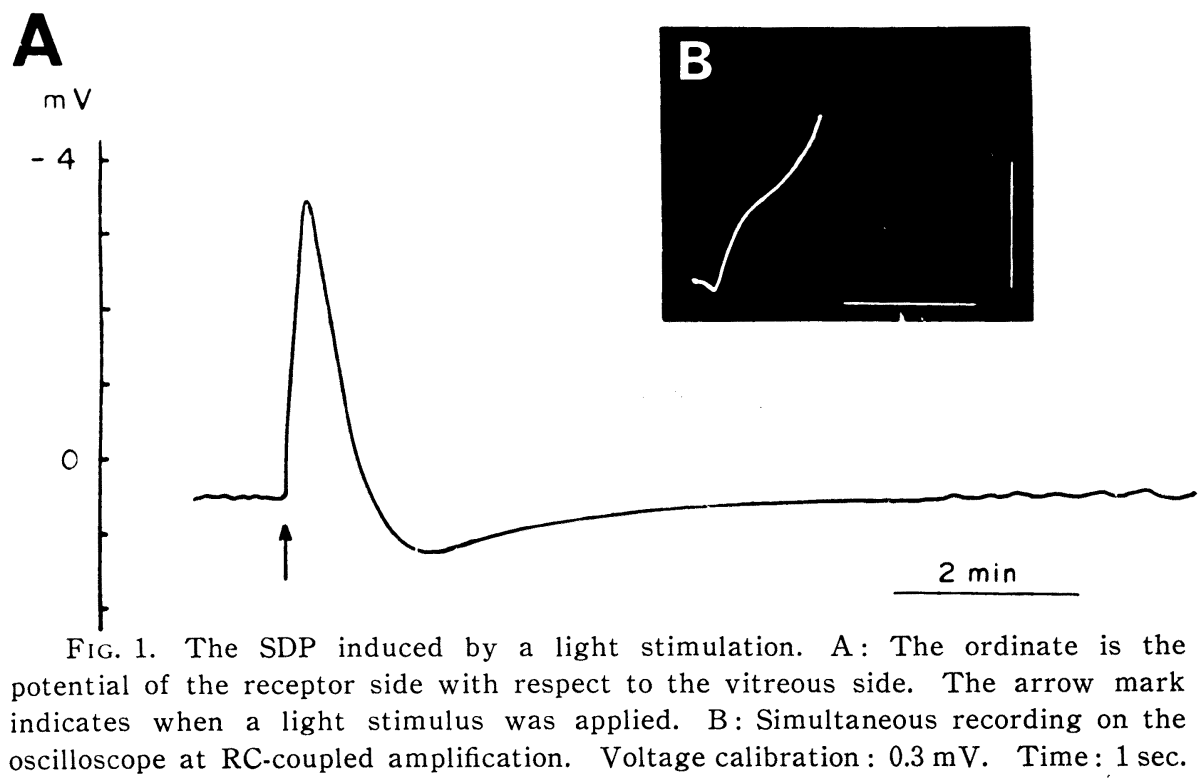

been applied to the retina. After a brief deflection which is due to the ERG (FIG. 1B), though the b-wave was not always seen distinctly on a direct writing recorder and oscilloscope, the potential of the receptor side became nagative. This negativity developed over a period of 1 to $2 \mathrm{~min}$, and attained a peak amplitude of $2-10 \mathrm{mV}$. The negative potential was followed by a smaller and longer lasting positive phase.

FIG. 2A shows a diagram of the SDP to analyze its amplitude and shape. $E_{1}$ and $E_{2}$ are the peak amplitude of the negative and the positive potential change respectively. $t_{1}$ and $t_{2}$ are the duration from the time of the initial light stimulation until the time attained a peak of the negative and the positive shift respectively. As shown in FIG. $2 \mathrm{~B}, \mathrm{C}$ and $\mathrm{D}$, there are the simple 

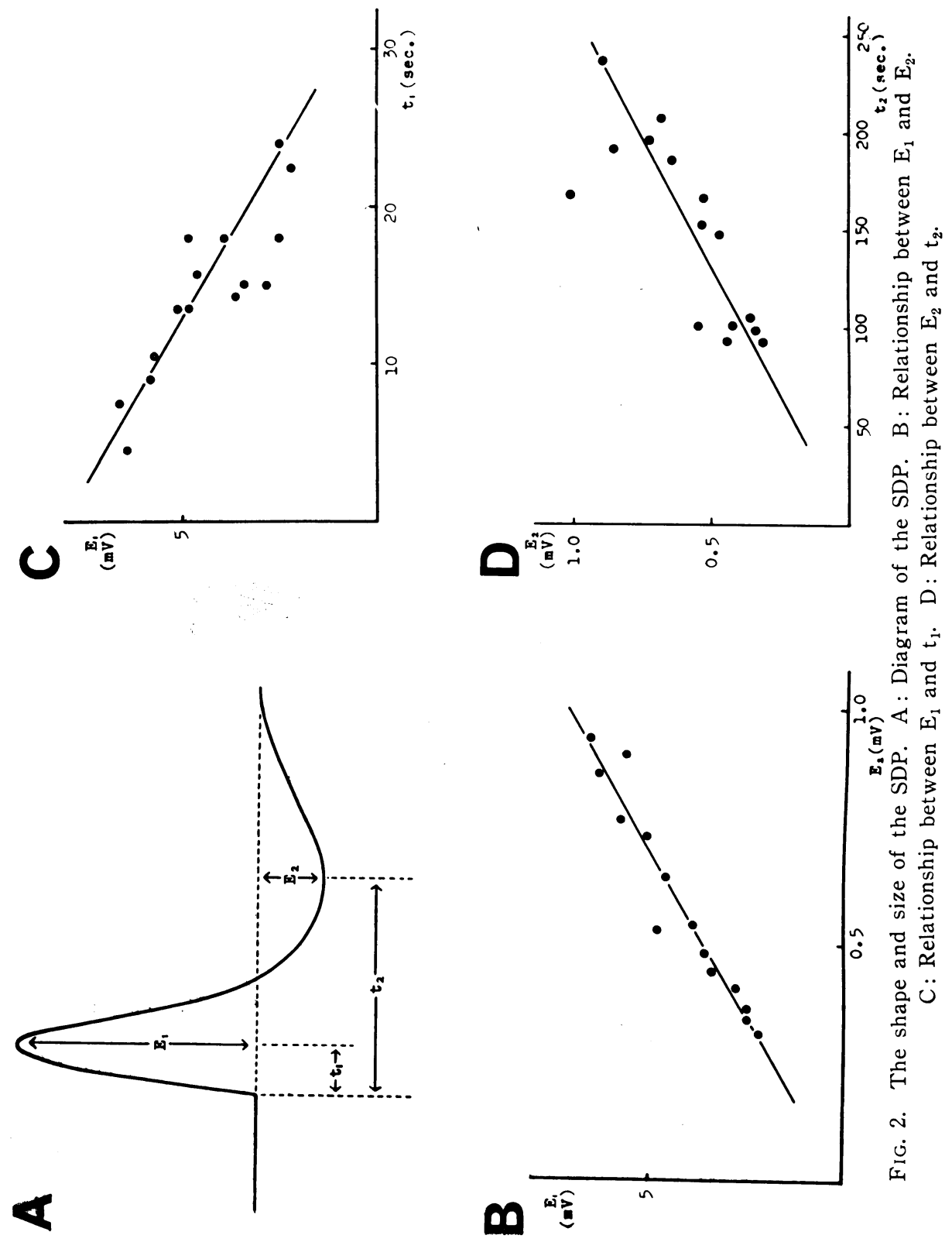
relationship between $E_{1}, E_{2}, t_{1}$ and $t_{2}$, and the equation derived was:

$$
\mathrm{E}_{1}=6.07 \mathrm{E}_{2}=-0.152 \mathrm{t}_{1}+6.54=0.0006 \mathrm{t}_{2}
$$

2. Recovery time for the SDP. The time course of the recovery of the SDP was observed by measurements of the amplitude of the SDP eliciting by the second light stimulus applied to the retina with different intervals after the application of the first light stimulus. The actual records obtained in an experiment of this kind are shown in FIG. 3. Within $8 \mathrm{~min}$ following the first effective light stimulus, the next SDP could not be obtained by the second stimulus, though the amplitude ERG was recovered almost completely. However, 10 min later, a small SDP was elicited after the generation of ERG. The amplitude of the SDP was increased when the interval between two light stimuli was longer and it reached a maximal value at about $30 \mathrm{~min}$ interval. Unfortunately, it was not possible to measure the exact latency of the SDP because of the b-wave superimposed on the initial phase of the SDP. However, as indicated in FIG. 3, when the interval between two light stimuli was longer, the apparent latency of the SDP detected upon the b-wave became shorter. In an experiment with 25 min interval, it was difficult to discriminate between the initial phase of $b$-wave and that of the SDP.

The time course of the recovery was somewhat different according to retinal preparation individually. As the amplitude of the SDP was increased, the minimum interval to elicite the second SDP became somewhat longer. However, the SDP having a constant amplitude could be easily obtained at a constant interval for a period of several hours.

3. Effect of the intensity of stimulating light. In order to examine the relation between the amplitude of the SDP and the intensity of stimulating light, light stimuli of different intensities were applied with $10 \mathrm{~min}$ interval to the retina. The relative intensity of light was varied by a set of neutral density filters, which were inserted in the pathway of light. The intensity of the light stimulus is indicated by the total density of the neutral filters. As shown in TABLE 1, it was found that regardless of the intensity of stimula-

TABLE 1.

Effect of stimulating light intensities. The intensity of light stımulus is indicated by the total density of the neutral filters.

\begin{tabular}{c|lllr}
\hline Log of the intensity & $\mathrm{E}_{1}$ & \multicolumn{1}{c}{$\mathrm{E}_{2}$} & $\mathrm{t}_{1}$ & $\mathrm{t}_{2}$ \\
\hline 0 & $3.46 \mathrm{mV}$ & $0.46 \mathrm{mV}$ & $4.2 \mathrm{sec}$ & $105.6 \mathrm{sec}$ \\
-1 & 3.42 & 0.40 & 5.7 & 100.2 \\
-2 & 3.42 & 0.44 & 6.3 & 98.6 \\
-3 & 3.42 & 0.44 & 6.0 & 112.5 \\
\hline
\end{tabular}



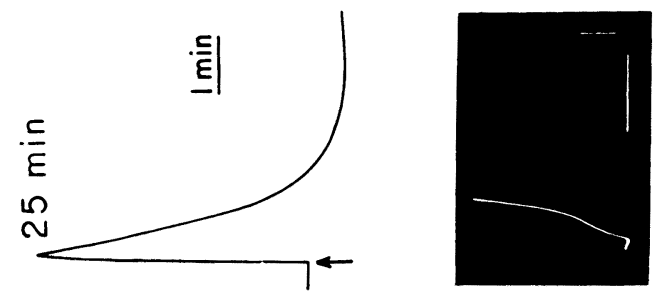

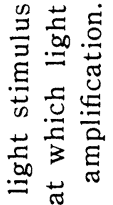
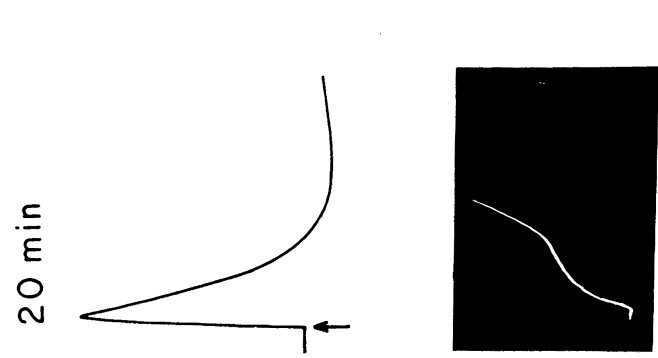

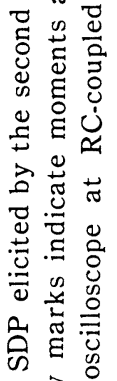
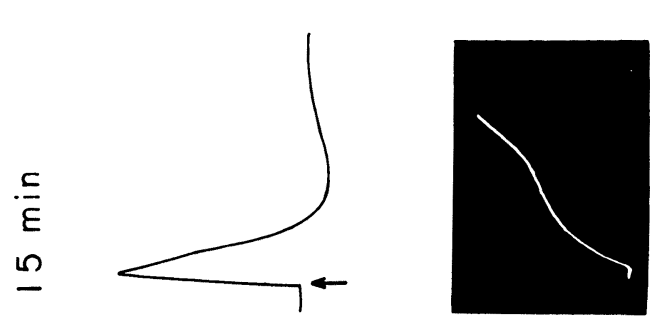

is

敋安

¿

㟧莺告

至.

苍范范

‡
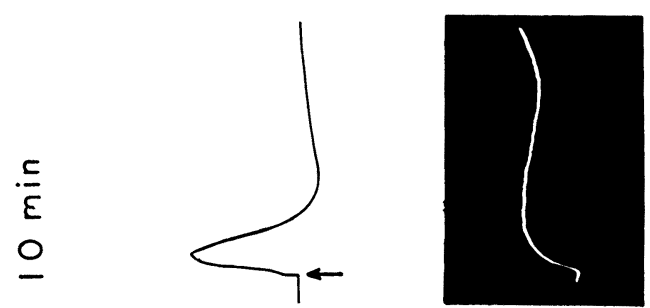

岁范

도

品证

证

言 군

๘

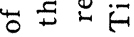

怘离岕文

药

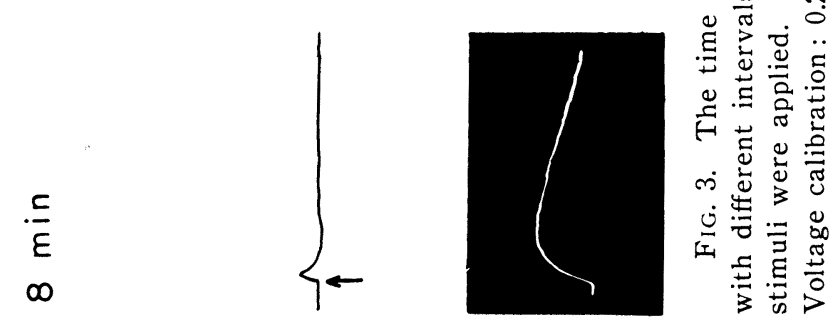

$3 \mathrm{mV}$ 
tion beyond the threshold, the amplitude of the $\operatorname{SDP}\left(\mathrm{E}_{1}\right.$ and $\left.\mathrm{E}_{2}\right)$ was always the same, though it is well known that the amplitude of the ERG is roughly proportional to the log of stimulus intensity. The finding that the SDP evoked by light stimulation obeys the all-or-none law indicates that any changes in amplitude of the SDP following an application of some agent should be due to the direct action on the responsing site in the retina.

4. Effect of electric stimulation. It is known that the spreading cortical depression is elicited by a dc current across the cortex, and that the threshold is lower when the active electrode on the surface of the cortex is negative (LEÃo and MORRISON, 1945; MARSHALL, 1959). Therefore, to clarify the effectiveness of electric stimulus on the elicitation of the SDP in the retina, a dc current of $0.01-0.84 \mathrm{~mA}$ was applied for $1 \mathrm{msec}$ across the retina. An electric current flowing between two compartments passed through the holes in the separating plates and the retina. When both sides of the retina were bathed by the initial control solution, regardless of direction of current, an electric stimulus did not evoke the SDP. However, by the presences of a $15 \mathrm{mM} \mathrm{Cl}$ solution on the receptor side and of a $\mathrm{Cl}$-free solution on the vitreous side, it was found that, when electrode on the receptor side of the retina was positive, a dc current of $0.23-0.28 \mathrm{~mA}$ applied for $1 \mathrm{msec}$ evoked the SDP, though the response was not elicited by a current of opposite direction.

5. Transretinal impedance change during the SDP. Since the SDP having a constant amplitude could be easily elicited by a light stimulus at a constant interval as described before, it was possible to compare the potential change with the transretinal impedance change by alternative measurements at a constant interval. FIGS. $4 \mathrm{~A}$ and $\mathrm{B}$ show the time course of the transretinal $\mathrm{dc}$ potential change and the corresponding impedance change following light stimulation respectively. The bridge unbalance was also recorded with an oscillograph as shown in FIG. 4C. Evidently, the observed change in the impedance represents a decrease in the electric resistance of the retina. When the impedance bridge was accurately balanced prior to stimulation, it was found that the bridge unbalance was caused by stimulation within $1 \mathrm{sec}$ (C). The record presented in FIG. 4B was taken by rectifying the output of the Wheatston bridge. The impedance change was monophasic and the peak of this change completely coincided with that of the negative shift in the SDP, but no clear-cut relationship between peak amplitudes of both changes could be defined. The elevation in conductivity was of the order of 2-4 per cent.

6. ERG during the SDP. In order to clarify changes in amplitude and shape of the ERG in the time course of evolution of the SDP, successive light stimuli applied to the retina. It was necessary to apply at least 1 min later 

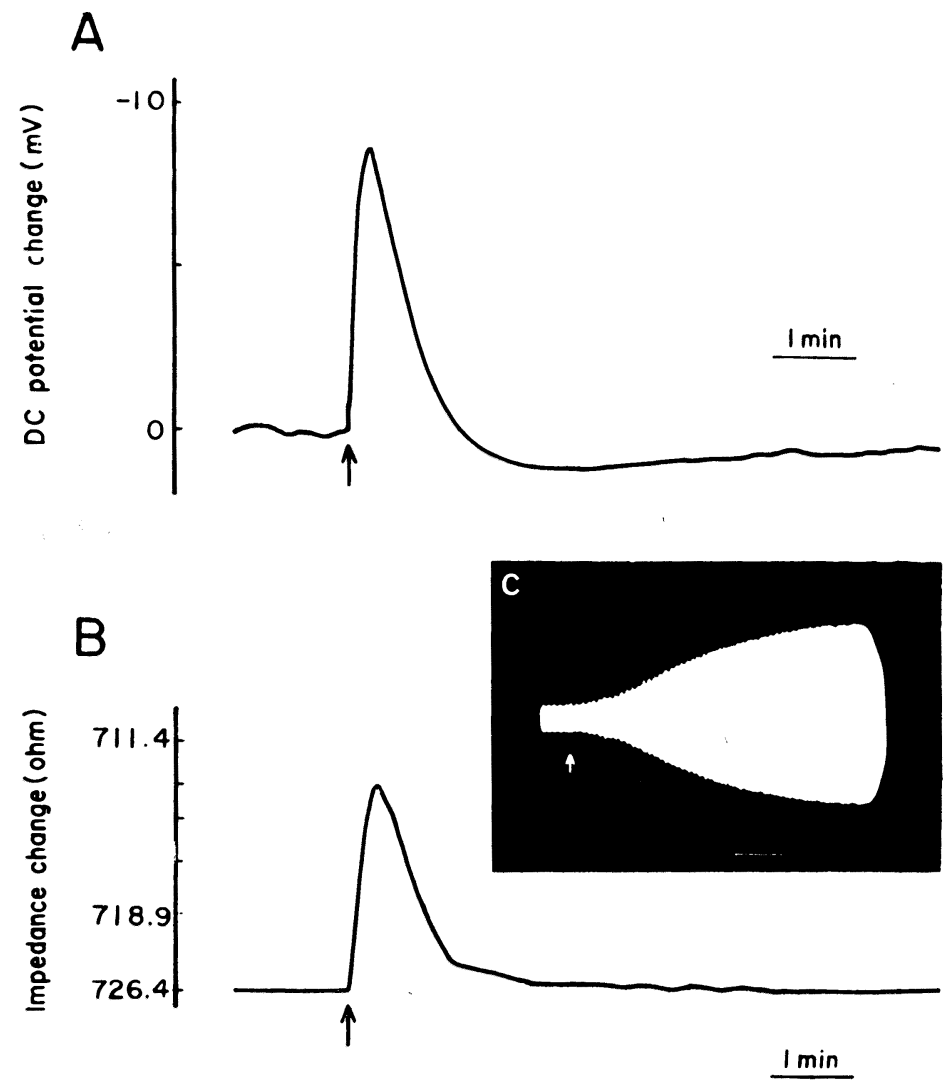

FIG. 4. Transretinal impedance change during the SDP. A: Transretinal dc potential change. The ordinate is the potential of the receptor side with respect to the vitreous side. The arrow mark indicates when a light stimulus was applied. B: Transretinal impedance change. The ordinate is the transretinal resistance value per $3.1 \mathrm{~mm}^{2}$ of tissue surface area. C: Simultaneous recording on the oscilloscope. Time: $5 \mathrm{sec}$. Alternating current is $1000 \mathrm{cycle} / \mathrm{sec}$.

after the preceding light stimulation, because the amplitude of ERG became smaller than that of original ERG if intervals of stimuli were less than $1 \mathrm{~min}$. The changes in amplitude of ERG to a single stimulus during the SDP are shown in FIG. 5B. The first light stimulation applied to the retina at the point (a) in FIG. 5A. The evolution of the SDP was observed after the generation of ERG. At the point (b), but just as the slow negative potential was decreasing, the b-wave was not seen and a small a-wave alone was observed. At the point $(c)$, that was the peak of the slow positive potential, the generation of a small b-wave was detected. After that, at the points (d), (e) and ( $f$ ), the amplitude of the b-wave increased gradually, and the point ( $g$ ), a new 

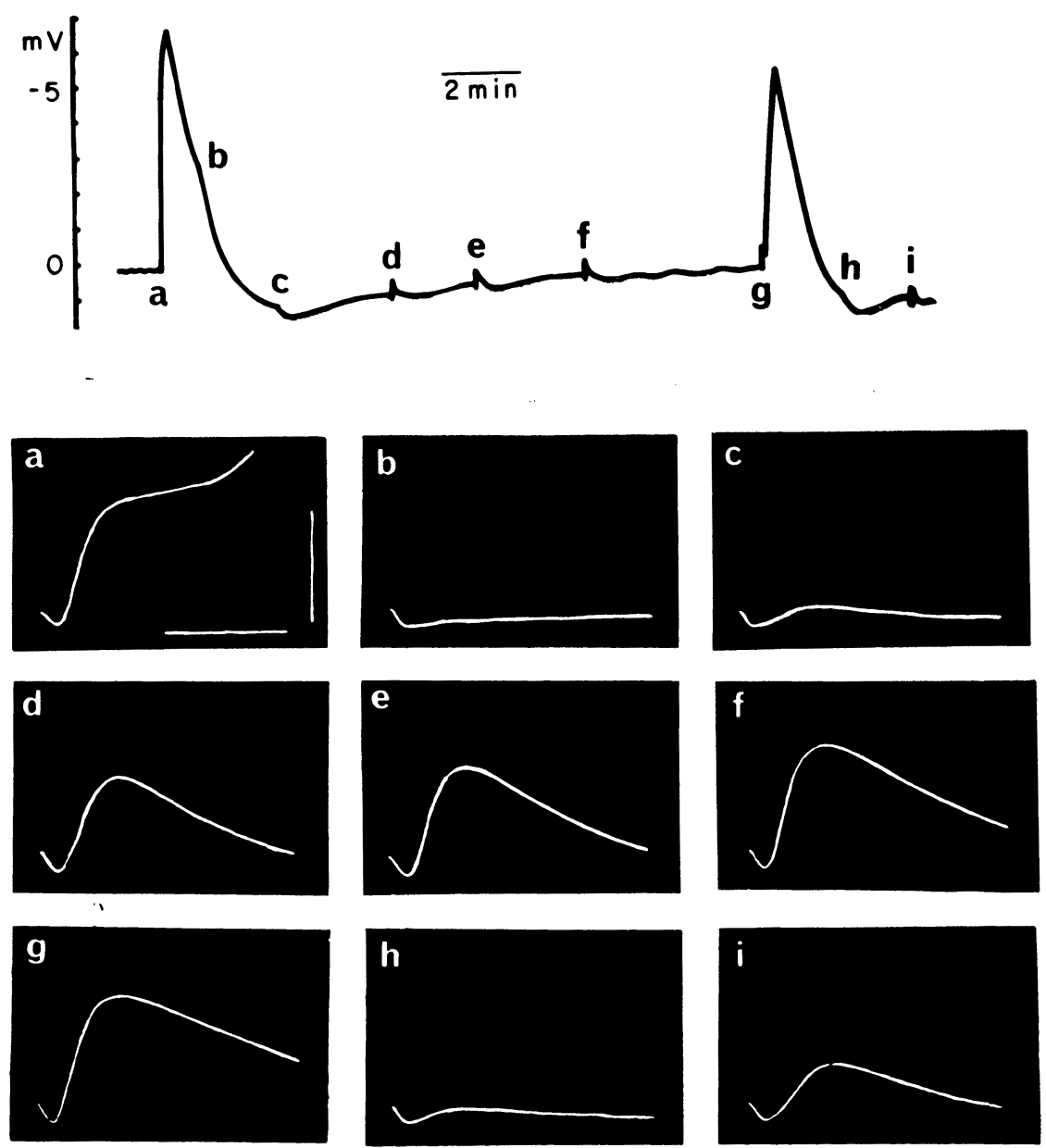

Fig. 5. ERG during the SDP. A: Transretinal dc potential change. The ordinate is the potential of the receptor side with respect to the vitreous side. Points $a, b, c, d, e, f, g, h$ and $i$ indicate when light stimuli were applied to the retina. B: Simultaneous recordings on the oscilloscope at $\mathrm{RC}$-coupled amplification at each point. Voltage calibration : $0.5 \mathrm{mV}$. Time: $1 \mathrm{sec}$.

SDP was evoked by a light stimulation. These facts indicate that the $b$-wave is completely depressed by the SDP, but it is not clear whether a-wave is affected during the SDP. A more precise demonstration of this problem was provided by the following experiment.

An attempt was made to inhibit the generation of $b$-wave by replacing a solution on the receptor side with a solution containing $51.8 \mathrm{mM} \mathrm{Na}, 20 \mathrm{mM} \mathrm{K}$ and $15 \mathrm{mM} \mathrm{Cl}$ ion concentrations. In this case, sodium sulfate in the solution on the receptor side was partially replaced by potassium sulfate and sucrose. The solution on the vitreous side was a Cl-free solution. As shown in FIG. 6, 

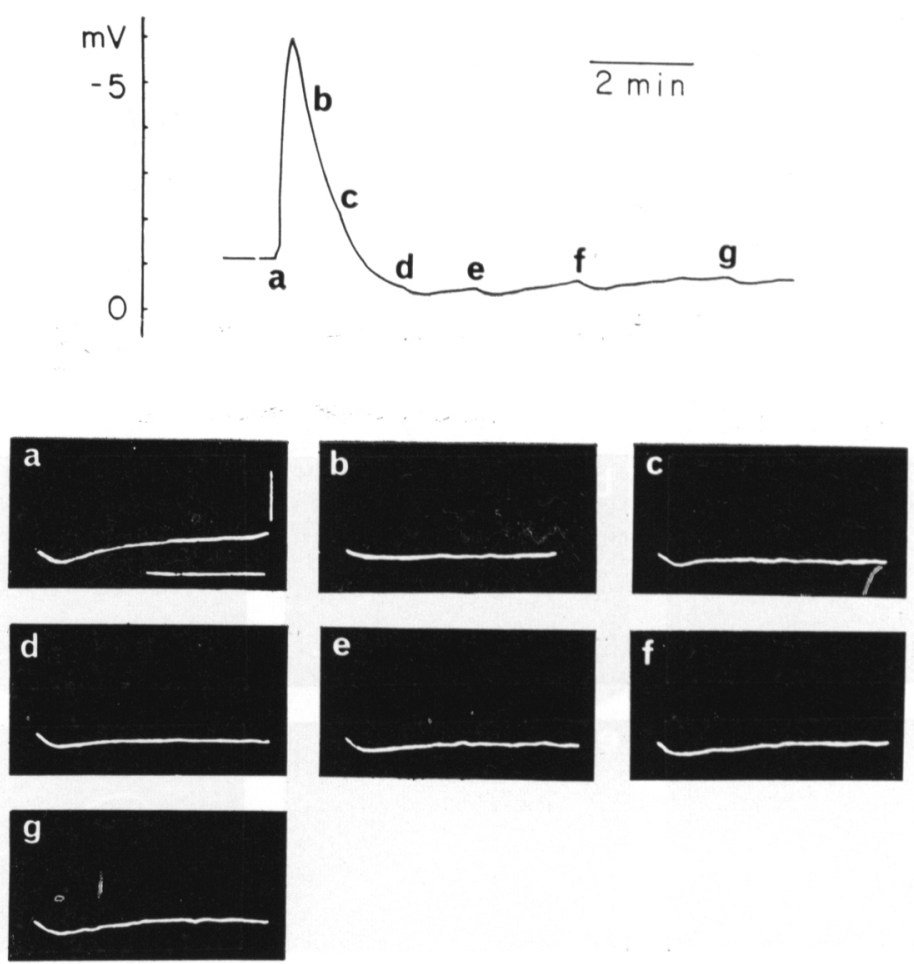

FIG. 6. Effect of the SDP on the a-wave. A: Transretinal dc potential change. The ordinate is the potential of the receptor side with respect to the vitreous side. Points $a, b, c, d, e, f$ and $g$ indicate when light stimuli were applied to the retina. B: Simultaneous recordings on the oscilloscope at $\mathrm{RC}$-coupled amplification at each point. Voltage calibration: $0.1 \mathrm{mV}$. Time: $1 \mathrm{sec}$.

after abolishment of the b-wave, a light stimulus was still capable to elicite the SDP after appearence of the a-wave. The first light stimulation applied to the retina at the point (a) in FIG. 6A. The evolution of the SDP was observed after the generation of a-wave. At the point (b), but just as the slow negative potential was decreasing a little from a peak of this potential change, the amplitude of the a-wave was declined remarkably. However, at the point (c), when the transretinal dc potential was approaching to its initial steadystate value, the a-wave was restored almost its original amplitude. After that, at the points (d), (e), (f) and (g), the amplitude and shape of the a-wave were similar to that of the point (a). 


\section{DISCUSSION}

Spreading cortical depression is a well known phenomenon of cortical electrophysiology ever since its initial description and definition in scientific terms as a specific entity by LEÃO (1944). In the case of excised retina, BARLOW (1953) and Gouras (1958) have observed a similar phenomenon with spreading cortical depression in the frog retinal preparation. However, the origin and characteristics of this slow potential change observed in the retina are not fully understood.

The results obtained in the present study show clearly that the SDP can be evoked in the retina by one of the light, mechanical and electrical stimulations in solutions with low extracellular chloride concentrations. The SDP are characterized as a biphasic transretinal dc potential change that the surface of the receptor side becomes first negative with respect to that of the vitreous side and then positive. The negative phase attains an amplitude of $2-10 \mathrm{mV}$ and the positive phase is considerably smaller. The entire process is reversible. It is important to remember that the SDP can not be induced in the initial control solution by any of physical stimuli above mentioned. As suggested by MARSHALL $(1950,1951)$ that spreading cortical depression is a phenomenon of the pathological cortex, the SDP also appears to occur in certain pathological state of the retina.

Although the retina is a part of the brain ontogenetically, there are two noticeable differences between this retinal response and spreading cortical depression. The first difference is the direction of the current of galvanic stimulus evoking the slow potential change when applied through the tissue. In the cortex, spreading depression can be started by the negative or positive polarization of the cortical surface, although the threshold current strength for positive polarization is much higher for negative polarization (LEÃO and MORRISON, 1945; MARSHALL, 1959). In the retina, the SDP could be elicited only by positive polarization of the receptor surface. The reason of such difference is not known exactly, but it might be attributable to structural and functional differences, because the retina might differentiate from brain so as to be fit for a visual function. The second difference is the trans-tissue impedance variations during the slow potential change. During spreading cortical depression, an impedance increase is observed, and the drop in conductivity is of the order of 10-20 per cent (LEÃO and MARTINS FERREIRA, 1953; FREYGang and LANDAU, 1955 ; VAN HARREVEld and Ochs, 1957). VAN HARREVELD $(1958,1962)$ have considered that the increase of resistivity is due to neuron swelling caused by the transport of water and chloride into apical dendrites. In contrast, in the excised retina, the transretinal impedance decreased during the SDP. This result is interpreted by supposing that an increase of extracellular volume in the retina is caused by a contraction of the 
Müller cells and also an increase of more highly conducting electrolyte in the extracellular space. There are some of the indirect evidences in support of this assumption. These are 1) the Müller cells belong to a group of the glia cells in the retina, 2) glia cells from tissue culture respond to electric stimuli with a slow contraction (CHANG and HILD, 1959), 3) the slow potential change in the retina is associated with retinal color change (GouRAs, 1958), 4) electric shock applied to neuroglia cells from tissue culture causes a rapid drop in impedance followed by a rise of a duration of 15-20 min (WALKER and TAKENAKA, 1965), 5) since the reduction in the amplitude of the SDP is related to the $\log$ of the extracellular potassium concentration (HANAwA, KUGE and MATSUMURA, in press), it seems more likely that sufficient intracellular potassium is released into the extracellular space during the SDP as observed in spreading cortical depression (BRINLEY, KANDEL and MARSHALL, 1960).

It is interesting to note that both $a$ - and $b$-wave were affected by the SDP but these effects differed from each other. It has been reported previously that the ERG is enhanced by the "inside cathod" polarizing current through the retina and depressed by "inside anode" (GRANIT and HeLme, 1939). Since the reduction in amplitude of the a-wave is not so remarkable as observed in b-wave and the a-wave restored its original amplitude when the negative potential shift returned to the original level, this effect, therefore, may be due to a local current flow produced by the SDP. As to the bwave, it was abolished at the peak of the negative potential shift and it had the long recovery time. It is well known that a high potassium concentration in the extracellular solution have a depressing effect on the b-wave (GRANIT, 1947 ; Furukawa and Hanawa, 1955 ; Hamasaki, 1964 ; Hanawa, Kuge and MATSUMURA, 1967). Since sufficient potassium may be released from the cells into the extracellular space during the SDP as described above, this depressive effect on the b-wave may be due to an increase of potassium concentration in the extracellular space.

\section{SUMMARY}

1. The slow depressive potential (SDP) has been investigated in the isolated frog retina deprived of the pigment epithelium. In this preparation, the SDP could be evoked easily by photic, mechanical or electrical stimulation with applying a $15 \mathrm{mM} \mathrm{Cl}$ solution on the receptor side and of a $\mathrm{Cl}$-free solution on the vitreous side.

2. The SDP was characterized as a biphasic transretinal dc potential change revealing the surface of the receptor side to be negative with respect to that of the vitreous side at first and then positive.

3. The SDP was definitely an 'all-or-none' response.

4. The SDP was elicited by a dc current across the retina when the electrode 
on the receptor side was positive.

5. Transretinal impedance decreased during the SDP, and the elevation in conductivity was of the order of 2-4 per cent.

6. The a- and b-wave was affected by the SDP. The b-wave abolished at the peak of the negative potential shift and it had the long recovery time. The effect on the a-wave was not so remarkable as observed on b-wave and it restored its original amplitude when the negative potential shift returned to the original level.

7. Observations from this study suggested that an increase of extracellular volume caused by contractions of Müller cells and an increase of potassium ion concentration in the extracellular space could be expected during the SDP.

We are indebted to Prof. E. KIMURA for his invaluable discussion and the preparation of the manuscript. A part of the expense of this work was defrayed by a grant of Ministry of Education.

\section{REFERENCES}

1) Barlow, H.B. (1953). Action potentials from frog's retina. J. Physiol. 119, 58-68.

2) Brinley, F. J., Kandel, E.R. And Marshall, W.H. (1960). Potassium outflux from rabbit cortex during spreading depression. J. Neurophysiol. 23, 246-256.

3) Chang, J. J. And Hild, W. (1959). Contractile responses to electrical stimulation of glial cells from the mammalian central nervous system cultivated in vitro. $J$. cell \& comp. Physiol. 53, 139-144.

4) Freygang, W.H. And Landau, W.M. (1955). Some relations between resistivity and electrical activity in cerebral cortex of cat. J. cell \& comp. Physiol. 45, 377392.

5) Furukawa, T. and Hanawa, I. (1955). Effects of some common cations on electroretinogram of the toad. Jap. J. Physiol. 5, 289-300.

6) Gouras, P. (1958). Spreading depression of activity in amphibian retina. Am. J. Physiol. 195, 28-32.

7) Granit, R. and Helme, T. (1939). Changes in retinal excitability due to polarization and some observation on the relation between the responses in retina and nerve. J. Neurophysiol. 2, 556-565.

8) Granit, R. (1947). Sensory mechanisms of the retina. Oxford: Oxford University Press.

9) HAMASAKI, D. I. (1964). The electroretinogram after application of various substances to the isolated retina. J. Physiol. 173, 449-458.

10) Hanawa, I., Kuge, K. and Matsumura, K. (1967). Effects of some common ions on the transretinal $\mathrm{dc}$ potential and the electroretinogram of the isolated frog retina. Jap. J. Physiol. 17, 1-20.

11) Hanawa, I., Kuge, K. And Matsumura, K. Mechanism of the slow depressive potential production in the isolated frog retina. Jap. J. Physiol. in press.

12) LEÃo, A. A.P. (1944). Spreading depression of activity in cerebral cortex. J. Neurophysiol. 7, 359-390.

13) Le Ão, A. A. P. And Morrison, R.S. (1945). Propagation of spreading cortical depression. J. Neurophysiol. 8, 33-45.

14) Leão, A. A. P. And Martins Ferreira, H. (1953). Alteracao da impedancia elec- 
trica no decurso da depressao alastrante da actividate do cortex cerebral. Anais acad. brasil. cienc. 25, 259-266.

15) Marshall, W.H. (1950). Relation of dehydration of brain to spreading depression of LEÃO. EEG \& Clin. Neurophysiol. 2, 177-185.

16) Marshail, W. H. And Essig, C.F. (1951). Relation of air exposure of cortex to spreading depression of LEÃO. J. Neurophysiol. 14, 265-273.

17) Marshall, W.H. (1959). Spreading cortical depression of LEÃo. Physiol. Rev. 39, 239-279.

18) Van Harreveld, A. And Ochs, S. (1956). Cerebral impedance changes after circulately arrest. Am. J. Physiol. 187, 180-192.

19) Van Harreveld, A. (1958). Changes in the diameter of apical dendrites during spreading depression. Am. J. Physiol. 192, 457-463.

20) Van Harreveld, A. (1962). Water and electrolyte distribution in central nervous system. Fed. Proc. 21, 659-664.

21) Walker, F. W. And TAkenaka, T. (1965). Electric impedance on neuroglia in vitro: Exptl. Neurol. 11, 277-287. 